\title{
Study on Change of Wool Fineness with Age of Alxa Bactrian Camel
}

\author{
Junyan Bai ${ }^{1,2}$, Ren Tao Di Wu' ${ }^{2}$ Le Ma Dao², Di Bao², Qiang Zhang² and Xing Hua Tian ${ }^{3}$
}

${ }^{1}$ College of Animal Science and Technology, Henan University of Science and

Technology, Luoyang 471023, China

${ }^{2}$ Institute of Animal, Alxa of Inner Mongolia, Bayanhaote 750306, China

${ }^{3}$ School of Life Sciences, Henan Universiry, Kaifeng 475000, China

\begin{abstract}
A B S T R A C T
In this study, SPSS17.0 software was used to analyze the wool fineness of 1079 Alxa Bactrian camels. The results showed that the wool fineness of male camel was significantly higher than that of female camel $(\mathrm{P}<0.05)$. At the age of $2-7$, the fluff fineness of male and female camel increased with age, At the age of 8-10 years, the fluff fineness of male and female camel has no obvious change trend with the increase of age. The best regression equation of male camel's wool fineness to age is quadratic regression equation: $\mathrm{Y}=15.971+0.409 \mathrm{X}-0.008 \mathrm{X}^{2}$, the fitting degree is 0.983 , the fitting effect is very good. The best regression equation of female camel's wool fineness to age is also a quadratic regression equation: $\mathrm{Y}=15.597+0.564 \mathrm{X}-0.030 \mathrm{X}^{2}$, the fitting degree is 0.873 , the fitting effect is better.
\end{abstract}

Article Information
Received 16 January 2020
Revised 10 February 2020
Accepted 14 February 2020
Available online 08 June 2021
Authors' Contribution
JB conceived and designed the study
and conducted the lab work. RTDW
analyzed the data and wrote the arti-
cle. LMD and QZ helped in sampling.
DB and LMD helped in analysis of
data.
Key words
Alxa bactrian camels, Wool fineness,
Regression analysis

$\mathrm{B}$ actrian camels have been tamed by human beings long before, which are docile, easy to ride and suitable for carrying loads, so they are usually used as tools for riding instead of walk among the people in desert areas, and meanwhile, they can provide livestock products such as meat, milk and fur. Furthermore, they have played a significant role in the human development and desert conquering. In recent years, domestic and foreign researches regarding genetic diversity (Wuren et al., 2017) and organization structure (Ye et al., 2014a, b) of Bactrian camels have achieved progress. Alxa Bactrian camel is an ancient camel species with a long history and the largest number in China, mainly distributed in Alxa Left Banner and Alxa Right Banner in Inner Mongolia. The cashmere of Bactrian camel is the leader of textile industry raw materials. Camel cashmere has the characteristics of light fitting, soft and fluffy, smooth and delicate, durable, which is incomparable to down and other cotton, wool and chemical fiber products. In this study, the wool fineness of Alxa Bactrian camel was analyzed to further understand the wool production characteristics of different sexes and ages of Bactrian camel, so as to provide reference for camel breeding and wool production and processing.

\footnotetext{
* Corresponding author: byezi@163.com; Wurenl223@ vip.sina.corn

0030-9923/2021/0004-1599 \$ 9.00/0

Copyright 2021 Zoological Society of Pakistan
}

\section{Materials and methods}

Alxa Bactrian camels 1079 in the experiment came from the left banner of Alashan, and the villi were sampled at the back of scapula on the side of the Bactrian camel. The collected fluff was placed on the black fluff board to select the fluff fiber with pointed tweezers and remove the coarse wool. The fineness of villi was measured by beion F6 fiber fineness analyzer. The main steps involved were as follows: The villi were cleared with alcohol, cut with scissors and placed on glass slides with ether. The glass slides were placed in the instrument for determination of fineness. SPSS17.0 software was used for regression analysis.

\section{Results and discussion}

Figure 1 shows the normal distribution of wool fineness of Alxa Bactrian camel. It can be seen that the average wool fineness of male camel is $17.510 \mu \mathrm{m}$, and that of female camel is $17.420 \mu \mathrm{m}$. The wool fineness of male camel is significantly higher than that of female camel $(\mathrm{P}<$ 0.05). Liu et al. (2009) showed that the average fineness of fine hair of Qinghai Bactrian camel was $16.32 \mu \mathrm{m}$. Azha et al. (2012) showed that the wool fineness of Xinjiang Mulei Bactrian camel was between 15.63-16.15 $\mu \mathrm{m}$. Obviously, the wool fineness of Alxa Bactrian camel in this study is thicker than that of Qinghai Bactrian camel and Xinjiang Mulei long eyebrow Bactrian camel, which may be the difference between the varieties of Bactrian camel.

Figure 2 shows the change in trend of wool fineness with age of Alxa Bactrian camel. It can be seen that the 
Table I. Regression equation between the wool fineness and age of Alxa Bactrian Camel.

\begin{tabular}{lllll}
\hline Sex & Model & Regression equation & Significance p value & Fitting degree $\left(\mathbf{R}^{2}\right)$ \\
\hline Male camel & Linear & $\mathrm{Y}=16.204+0.313 \mathrm{X}$ & 0.000 & 0.982 \\
& Logerithmic & $\mathrm{Y}=15.432+1.581 \log (\mathrm{X})$ & 0.000 & 0.954 \\
& Quadratic & $\mathrm{Y}=15.971+0.409 \mathrm{X}-0.008 \mathrm{X}^{2}$ & 0.000 & 0.983 \\
& Cubic & $\mathrm{Y}=15.970+0.409 \mathrm{X}-0.008 \mathrm{X}^{2}+8.838 \times 10^{-6} \mathrm{X}^{3}$ & 0.000 & 0.979 \\
Female camel & Linear & $\mathrm{Y}=16.484+0.201 \mathrm{X}$ & 0.001 & 0.784 \\
& Logerithmic & $\mathrm{Y}=15.888+1.074 \log (\mathrm{X})$ & 0.000 & 0.871 \\
& Quadratic & $\mathrm{Y}=15.597+0.564 \mathrm{X}-0.030 \mathrm{X}^{2}$ & 0.001 & 0.873 \\
& Cubic & $\mathrm{Y}=15.687+0.504 \mathrm{X}-0.019 \mathrm{X}^{2}+0.0006 \mathrm{X}^{3}$ & 0.005 & 0.848 \\
\hline
\end{tabular}

measurement value of wool fineness of male camel is always higher than that of female camel during the period of 2-10 years old. In the period of 2-7 years old, the wool fineness of male and female camels increased with age. From 8 to 10 years old, the wool fineness of male camel increases slowly with the increase of age, while that of female camel did not.

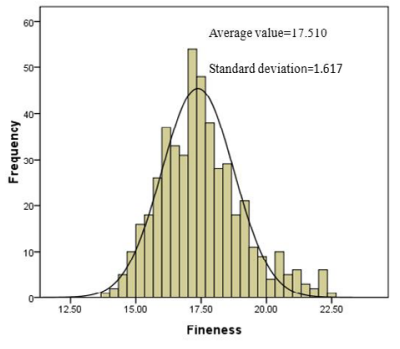

Male

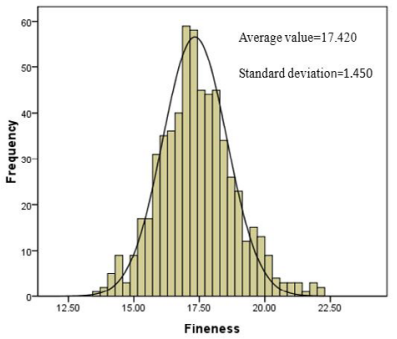

Female
Fig. 1. Distribution of wool fineness of Alxa bactrian camel.

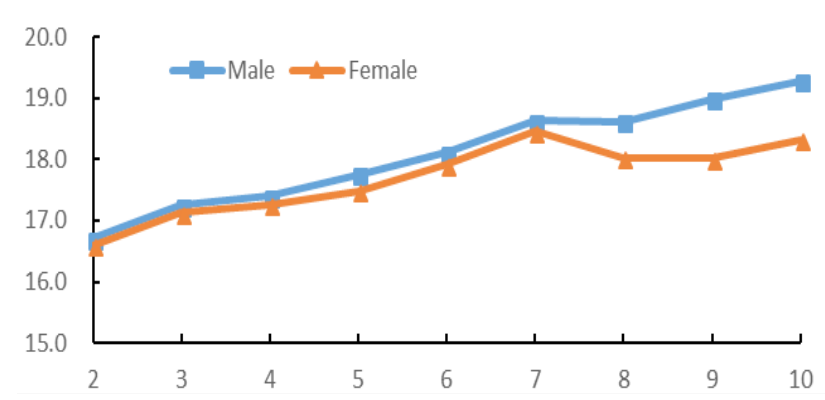

Fig. 2. The change trend of wool fineness with age in Alxa bactrian camel.

Figure 3 and Table I show the regression curve and equation of the wool fineness to age of Alxa Bactrian camel, It can be seen that the best regression equation of male camel's wool fineness to age is quadratic regression equation: $\quad \mathrm{Y}=15.971+0.409 \mathrm{X}-0.008 \mathrm{X}^{2}$, the fitting degree is 0.983 , the fitting effect is very good. The best regression equation of female camel's wool fineness to age is quadratic regression equation: $\mathrm{Y}=15.597+0.564 \mathrm{X}-$ $0.030 \mathrm{X}^{2}$, the fitting degree is 0.873 , the fitting effect is better.

This study also showed that the fineness of the hair of Bactrian camel increased with the increase of age, especially after the age of 7 , the fineness of the hair of Bactrian camel increased. Obviously, therefore, Bactrian camel over 10 years old eliminated or raised less. In addition, there are varieties, feeding methods, temperature and so on, which will also have a certain impact on the cashmere fineness of bactrian camel.
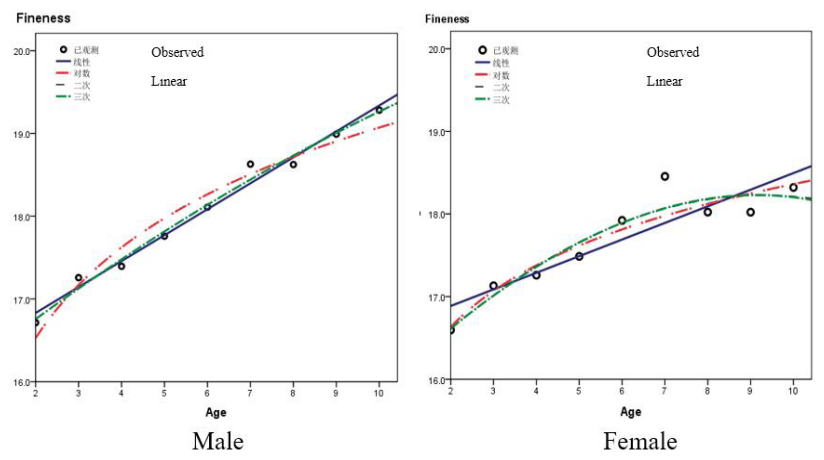

Fig. 3. Regression curve of wool fineness to age of Alxa bactrian camel.

\section{Acknowledgements}

Sincere gratitude goes to the sponsor of Alxa League Science and Technology Project in Inner Mongolia (2012-12).

\section{Statement of conflict of interest}

The authors have declared no conflict of interest. 


\section{References}

Azha, T., Ha. E.A.L., Ha, D.X. and La, Z.T., 2012. Xinjiang Anim. Husb., 5: 58-60.

Liu, H.X., Zhang, X.Q. and Feng, D.Z., 2009. Livest. Poult. Indust., 6: 4-5.

Wang, H.J., Ma, K.M., Liu, Z.H., Jin, D.Z. and Wei, W.Q., 2016. J. Camel Pract. Res., 23: 241-246. https://doi.org/10.5958/2277-8934.2016.00041.2

Wuren, T.D., Bai, J.Y., Dao, L.M., Bao, D. and Zhang,
Q., 2017. Hubei agric. Sci., 56: 2913-2915.

Ye, W.L., Wang, F.L., Xie, Z.H., Wang, Y.G., Lin, B. and Wang, J.L., 2014a. J. Camel Pract. Res., 21: 191-198. https://doi.org/10.5958/22778934.2014.00033.2

Ye, W.L., Xie, Z.H., Wang, F.L., Gen, X., Dong, S. and Wang, J.L. 2014b. J. Camel Pract. Res., 21: 103-109. https://doi.org/10.5958/22778934.2014.00020.4 